\title{
Science/education portraits II: Pre-tertiary and undergraduate research mentors should consider publication as project endpoint
}

\begin{abstract}
Scholarly publication is a common productivity metric for researchers of all levels. Despite the benefits of publications to pre-undergraduate and undergraduate research students, they tend to be less productive in terms of publication counts than graduate research students. Here, I narrate my personal experiences as an attempt to try to convince fellow pre-tertiary and undergraduate research mentors research mentors to consider publications as a suitable endpoint for any research projects, as they can have lasting mutual benefits to the student / mentee, and project mentors.
\end{abstract}

Keywords: research projects, publications, mutual benefits, project closure, computing
Volume 7 Issue 2 - 2018

\author{
Maurice HT Ling ${ }^{1,2}$ \\ 'Colossus Technologies LLP, Republic of Singapore \\ ${ }^{2} \mathrm{HOHY}$ PTE LTD, Republic of Singapore
}
Correspondence: Maurice HT Ling, Colossus Technologies LLP, 8 Burns Road, Trivex, Singapore 369977, Republic of Singapore, Tel +659666 9233,
Email mauriceling@colossus-tech.com

Received: February 09, 2018 | Published: April 26, 2018

\section{Introduction}

Research experience is an important component of science education due to its many benefits ${ }^{1-4}$ from the perspective of the student or mentee; including better understanding of research process, ${ }^{5}$ increased motivation ${ }^{6}$ and active learning, ${ }^{7}$ higher cumulative grade point averages, ${ }^{8}$ and a platform for developing analytical skills and a deeper understanding of theoretical principles ${ }^{9}$ and context. ${ }^{10}$ Besides the mentee, mentors had also reported substantial benefits, ${ }^{11,12}$ which has been supported by my own experiences. ${ }^{13}$ One of the mutually beneficial research outcomes is in the form of research publications. Although it can be challenging to quantify overall research productivity in terms of publications from graduate and undergraduate research separately, it can be generally safe to expect lower publication counts from undergraduate research compared to graduate research. A survey study by Morales et al. ${ }^{14}$ on 536 faculty members showed that $39 \%$ of undergraduate research students mentored in the preceding 5 years did not publish while a survey study by Hall et al. ${ }^{15}$ on 280 graduate students showed that $13.6 \%$ did not publish. It can then be plausible to conceive that pre-undergraduate/pre-tertiary research students are less likely to publish compared to undergraduate students. However, it had been shown that scholarly publications helps students / mentees in significant ways; ${ }^{14}$ including compete more successfully as applicants to graduate school, ${ }^{16}$ and more successful research careers. ${ }^{17}$

In this article, I narrate my personal experiences as an attempt to try to convince fellow pre-tertiary and undergraduate research mentors to consider publications as a suitable endpoint for any research projects. A successful scholarly publication signifies a strong recognition of the mentees' work and can be viewed by the mentees as an acceptance or rite of passage into the scientific research world. ${ }^{18}$ Personal narration, sometimes also known as storytelling, ${ }^{19}$ is autobiographic in nature with rich emotional and contextual cues ${ }^{20}$ that are required to describe the human experience. ${ }^{21}$ Thus, personal narration puts the human into the story. ${ }^{22,23}$ Personal narration also overlaps with participatory action research where reflective self-inquiry is carried out with the intention to improve subsequent actions. ${ }^{24-26}$

\section{Fighting for my doctoral scholarships}

In many fields of science, one of the main highlights of an early scientist's career is acceptance into a doctoral program and the subsequent convocation or commencement of a doctoral degree, commonly known as a $\mathrm{PhD}$. Gannon ${ }^{27}$ argues that a $\mathrm{PhD}$ is "an award to an expert who has proven their scientific worth" and such "scientific worth" usually takes the form of novel research, which is evident by scientific authorship in peer-reviewed publications. This led to the question by Hagen ${ }^{28}$ - how many papers does it take to make a PhD? By evaluating more than $400 \mathrm{PhD}$ dissertations, Hagen $^{28}$ estimated a baseline of 1.6 publications per dissertation. Hence, it can be safely assumed that critical hurdle for a $\mathrm{PhD}$ award is a successful publication. This has led to a notable shift towards $\mathrm{PhD}$ by prior publications, which is the usual route for a higher doctorate (such as, Doctor of Science). $\mathrm{PhD}$ by prior publications is where the author or prospective $\mathrm{PhD}$ awardee must make a coherent, original, and meaningful contribution to a field of knowledge. ${ }^{29}$ Hence, it can be safe to assume that the potential for applicants to graduate research programs; such as, a doctoral program; should demonstrate research and authoring abilities. As such, it is plausible to conceive that prior publications under the belt of the applicant will be viewed favourably.

This was the case with my own doctoral application to The University of Melbourne, Australia, in 2004. As I did my undergraduate and honours project in the same university, there was a scoring scheme, known as PhD entry score (PES), in which applicants were scored for scholarship placements. PES comprised of one-third honours entry score (HES) and two-thirds of honours year result. The third year in the Bachelor of Science comprised of 8 subjects (4 subjects per semester), and HES is calculated as the average of the top 7 subjects out of 8 subjects in the third year. Peer-reviewed publications were added on as bonus points to PES, at the rate of 2 points per publication, up to the maximum of 2 publications. With these numbers, I can calculate the value and impact of a peer-reviewed publication to my PES. One publication is equivalent to 2 bonus PES points, which is then equivalent to 6 HES points. Since HES is the average of 7 third year subjects, 6 HES points can be equivalent to 42 marks in third year subjects. Therefore, a peer-reviewed publication during graduate application during my time could be valued at nearly 
half of a third-year subject.

Although my case may be isolated, it does illustrate the potential impact of scholarly / peer-reviewed publications in the successful application to a graduate program. ${ }^{16}$ I was lucky to have presented my first publication on a project, which I did as partial fulfillment to the Advanced Diploma in Computing, in the inaugural Australian Undergraduate Students' Computing Conference (a peer-reviewed undergraduate conference); hence, able to claim 2 bonus PES points. If I had known of this way before my graduate application, I might be more diligent in my other research projects on hindsight. This experience made an impact on me.

\section{Mutual benefits from publishing pre- undergraduate research}

Due to my experience in fighting for my own doctoral scholarship and witnessing first-hand the value and impact of publications, I made a conscious decision to make publication as an endpoint during my subsequent years as a lecturer and project mentor. Over the 7 years (2009-2015), I had supervised 6 pre-university research projects, which generated 19 peer-reviewed publications as previously described. ${ }^{13}$ I do not side-step the fact that these publications contributed substantially to my career advancement and research goals. Yet, I do say that an equally important motive to publish preuniversity research projects is to accumulate credentials and build their portfolio for their future use; even though at that point in time, I am not entirely sure if my determination to push for publications, whenever possible, is a right choice.

The following case strengthened my convictions. I had a student whom did his final year project with me in his pursuit of a Diploma in Biotechnology, in Singapore. However, this student had examination phobia due to his previous experiences and was constantly unable to do well despite being capable in other technical skills. Nevertheless, his grades put him at disadvantage when he was applying for admission into an arts degree in an Australian university. He had considered that science is his interest but not suitable as his career and I respected his decision. If I recalled correctly, his grade-point average (GPA) is nearly 0.5 lower than entry requirement into his university of choice. By then, his final year project had been published in a peer-reviewed journal (for anonymity, I am not able to cite this publication). He had contacted me for advice during his application and I suggested that he should make copies of his published paper to append to his university application. He was accepted and had since completed his Bachelor of Arts from a university within the top 100 of Times Higher Education World University Rankings. I believe that his peer-reviewed publication helped to grant him admission into the university. This is supported by another of my ex-student's recount, ${ }^{18}$ "Looking back, I think the series of papers we wrote with Maurice was certainly a great boon to my $\mathrm{CV}$, and contributed to me getting into medical school."

Steve Jobs once said, "You can't connect the dots looking forward; you can only connect them looking backwards. So you have to trust that the dots will somehow connect in your future. You have to trust in something - your gut, destiny, life, karma, whatever. This approach has never let me down, and it has made all the difference in my life." This struck a chord in me - other than basing on my own experience with my own scholarship, I did not have other circumstantial evidence to triangulate ${ }^{30,31}$ the value or impact of publications to preundergraduate project students despite that being a logical conclusion.
Hence, I trust my own experience to forge ahead. With an ex-student evidently benefiting from having a peer-reviewed publication under his name and another ex-student's testament, I do have enough evidence for triangulation ${ }^{30,31}$ suggesting the value of publications to research students at the pre-undergraduate level.

\section{Conclusion}

The second habit in Stephen Covey's The 7 Habits of Highly Effective People ${ }^{32}$ is "Begin with the End in Mind". It is common for any academic research at the graduate level to have an end goal in mind, which is usually in the form of at least a peer-reviewed publication. My personal experience suggests that this objective should not be sole privilege of graduate research. As research mentors, we should consider peer-reviewed publication(s) as an aim in any academic research projects of all levels; graduate, undergraduate, and even preundergraduate. I hope that my experience is convincing enough for such consideration whenever possible - a peer-reviewed publication is a nice conclusion to an academic research project.

\section{Acknowledgements}

I wish to thank all my students and mentors for providing me with positive experiences, which strengthen my convictions down this path.

\section{Conflict of interest}

The author declares no conflict of interest.

\section{References}

1. Russell SH, Hancock MP, McCullough J. Benefits of undergraduate research experiences. Science(Washington). 2007;316(5824):548-9.

2. Thiry H, Weston TJ, Laursen SL, et al. The benefits of multi-year research experiences: differences in novice and experienced students' reported gains from undergraduate research. CBE Life Sci Educ. 2012;11(3):260-72.

3. Pearson RC, Crandall KJ, Dispennette K, et al. Students' Perceptions of an Applied Research Experience in an Undergraduate Exercise Science Course. Int J Exerc Sci. 2017;10(7):926-941.

4. Salto LM, Riggs ML, Delgado De Leon D, et al. Underrepresented minority high school and college students report STEM-pipeline sustaining gains after participating in the Loma Linda University Summer Health Disparities Research Program. PLoS One. 2014;9(9):e108497.

5. Krasny ME. Reflections on Nine Years of Conducting High School Research Programs. Journal of Natural Resources and Life Sciences Education. 1999;28:17-23.

6. Godin EA, Wormington SV, Perez T, et al. A Pharmacology-Based Enrichment Program for Undergraduates Promotes Interest in Science. CBE Life Sci Educ. 2015;14(4):ar40.

7. Lopatto D. Undergraduate Research Experiences Support Science Career Decisions and Active Learning. CBE-Life Sciences Education. 2007;6(4):297-306.

8. Haeger H, Fresquez C. Mentoring for Inclusion: The Impact of Mentoring on Undergraduate Researchers in the Sciences. CBE Life Sci Educ. 2016;15(3).

9. Via A, Blicher T, Bongcam-Rudloff E, et al. Best practices in bioinformatics training for life scientists. Brief Bioinformatics. 2013;14(5):528-37.

10. Ali K, Zahra D, McColl E, et al. Impact of early clinical exposure on the learning experience of undergraduate dental students. Eur J Dent Educ. 2018;22(1):e75-80. 
11. Ghosh R, Reio TG. Career benefits associated with mentoring for mentors: A meta-analysis. Journal of Vocational Behavior. 2013;83(1):106-116.

12. Petrella JK, Jung AP. Undergraduate Research: Importance, Benefits, and Challenges. Int J Exerc Sci. 2008;1(3):91-5.

13. Ling MH. A personal narrative of 6 pre-university research projects over 7 years (2009-2015) yielding 19 manuscripts. MOJ Proteomics \& Bioinformatics. 2017;6(3):00193.

14. Morales DX, Grineski SE, Collins TW. Increasing Research Productivity in Undergraduate Research Experiences: Exploring Predictors of Collaborative Faculty-Student Publications. CBE Life Sci Educ. 2017;16(3).

15. Hall JD, O’Connell AB, Cook JG. Predictors of Student Productivity in Biomedical Graduate School Applications. PLoS ONE. 2017;12(1):e0169121

16. Davis DJ, Warfield M. The importance of networking in the academic and professional experiences of racial minority students in the USA. Educational Research and Evaluation. 2011;17(2):97-113.

17. Horta H, Santos JM. The impact of publishing during $\mathrm{PhD}$ studies on career research publication, visibility, and collaborations. Research in Higher Education. 2016;57(1):28-50.

18. Chan OY, Keng BM, Ling MH. Science/Education Portraits I: Identifying Success Factors of Pre-Tertiary Bioinformatics Research Experience from Students' Perspective. Advances in Biotechnology and Microbiology. 2018;8(2):555734.

19. Dahlstrom MF. Using narratives and storytelling to communicate science with nonexpert audiences. Proc Natl Acad Sci U S A. 2014;111(Supplement 4):13614-13620.

20. Edwards SL. The Personal Narrative of a Nurse. J Holist Nurs. 2015;34(2):154-161.

21. Ingraham C. The Scope and Autonomy of Personal Narrative. Written Communication. 2016;34(1):54-74.

22. Hamm JA, Leonhardt BL. The Role of Interpersonal Connection,
Personal Narrative, and Metacognition in Integrative Psychotherapy for Schizophrenia: A Case Report. J Clin Psychol. 2016;72(2):132-141.

23. Bennett D, Reid A, Rowley J. Student musicians' experiences of reflexivity during internships: Personal narratives and complex modalities. International Journal of Music Education. 2017;35(3):460-475.

24. Baum F, MacDougall C, Smith D. Participatory action research. $J$ Epidemiol Community Health. 2006;60(10):854-857.

25. Apgar JM, Cohen PJ, Ratner BD, et al. Identifying opportunities to improve governance of aquatic agricultural systems through participatory action research. Ecology and Society. 2017;22(1):9.

26. Darby S. Making space for co-produced research 'impact': learning from a participatory action research case study. Area. 2017;49(2):230-7.

27. Gannon F. What is a PhD? EMBO Rep. 2006;7(11):1061.

28. Hagen NT. Deconstructing doctoral dissertations: how many papers does it take to make a PhD? Scientometrics. 2010;85(2):567-79.

29. de Granda-Orive JI, Villena-Garrido V. PhD by Prior Publication: An New Approach to the Doctoral Thesis. Arch Bronconeumol. 2018;54(1):56.

30. Hargis J, Cavanaugh C, Kamali T, et al. A federal higher education iPad mobile learning initiative: Triangulation of data to determine early effectiveness. Innovative Higher Education. 2014;39(1):45-57.

31. Yasuyuki M, Heike M. Revisiting the Roles of the University in Regional Economic Development: A Triangulation of Data. Growth and Change. 2017;48(4):787-804.

32. Covey SR. The 7 habits of highly effective people: Powerful lessons in personal change. New York: Simon and Schuster; 2013. 